\title{
Research on the Regulatory Path of Leading Cadres' Sexual Harassment*
}

\author{
Bo Han \\ Civil and Commercial Law School \\ Shandong University of Political Science and Law \\ Ji'nan, China
}

\begin{abstract}
Since the 18th National Congress of China, the party has become stricter and stricter, and the discipline requirements for leading cadres have also been strengthened. In the briefing of the officials of the fallen horses, the expression of unfair sexual relations with others is often mentioned. Although the anti-corruption struggle has achieved a decisive victory, the next step of anti-corruption needs to be further deepened. Therefore, the requirements for the life discipline of leading cadres should be further strengthened. The issue of sexual harassment of leading cadres should also be included in the scope of regulation so that the goal of strictly administering the party can be achieved. At the same time, most of the previous studies on sexual harassment of leading cadres are from a moral point of view, but it is believed that the problem of sexual harassment of leading cadres should be restrained from the institutional level, and the rule of law is the best means of governance. In the process of promoting the rule of law by government agencies, the medicine further regulates the direct relationship between the lower and lower levels, establishes the internal management system of the government agencies in line with China's reality, and at the same time, defines the sexual harassment more clearly, and transforms it from the moral category to the legal category.
\end{abstract}

Keywords-leading; cadres; sexual harassment; prevention and control

\section{INTRODUCTION}

Since the 18th National Congress of the Communist Party of China, the Party Central Committee with Comrade $\mathrm{Xi}$ Jinping has attached great importance to anti-corruption work and has issued a series of institutional guidelines. The most important of these is the "Regulations on Disciplinary Actions of the Communist Party of China" including political discipline, organizational discipline, and integrity discipline., mass discipline, work discipline, life discipline, six aspects. Among them, Article 135 on life discipline focuses on the regulation of unfair sexual relations with others. However, in practice, many sexual harassment has not developed to such a serious degree. Sometimes it is only harassment in speech or physical movements, which brings great obstacles to the identification and prescription of sexual harassment. At the same time, the central government

*This paper is the medium achievement of the school-level project of Research on Sexual Harassment Regulation Legislation of Shandong University of Political Science and Law in 2019 (Project No.: 2019F04B). demands anti-corruption struggle. To develop in depth, the requirements for leading cadres must be further improved. Therefore, it is necessary to further study the issue of sexual harassment of leading cadres and put forward practical and feasible ideas for prevention and control so as to better contribute to the fight against corruption.

\section{The Status Quo of PREVEntion And Control of LEADING CADRES' SEXUAL HARASSMENT}

Sexual harassment did not enter the Chinese public for a long time. Until the mid-1990s, scholars from different fields gradually introduced the concept of sexual harassment from foreign related fields, which made the concept of sexual harassment gradually known to the people. Catherine McKinnon was the first scholar to define sexual harassment. She defined sexual harassment as: "the nasty sexual requirements imposed on people under conditions of inequality of rights" and the process of using control to expand male power and domination. In this process, people gradually realized that many of the previous behaviors were abnormal, and gradually realized the great harm of sexual harassment. Therefore, the country also introduced many measures to prevent sexual harassment. However, the prevention and control of leading cadres' sexual harassment still has great problems The sexual harassment of leading cadres has the following characteristics:

The pattern of sexual harassment of leading cadres is often concealed. Because leading cadres are in a dominant position in the administrative organs, their relationship with their subordinates is a power relationship, and in the power relationship, the status of the two parties is not equal. The victims are often afraid of being persecuted or for reasons of reputational damage. Not willing to speak.

The impact of sexual harassment by leading cadres is relatively bad. Traditionally, China has emphasized the use of law as a teacher and the slogan as a teacher. It emphasizes the moral quality of officials and the virtues of politics. Therefore, it also puts higher standards on the moral quality of officials. However, China has traditionally had a strong negative evaluation of the behavior of morality in relation to sex. The sinister prostitution is the performance of this idea. Therefore, once an official has a problem of morality, he will be quickly amplified by the media, which will not only have 
a great impact on his reputation, but also bring harm to the overall image of public officials.

The forms of sexual harassment of leading cadres are more diverse. There is no anti-sexual harassment law in China, so there is no specific regulation on the form of sexual harassment, which is sometimes difficult to define clearly in practice. In particular, the distinction between legal and illegal behavior is sometimes difficult to define. The form of sexual harassment includes both verbal and behavioral aspects.

The sexual harassment of leading cadres has had a great impact on the image of the government. Therefore, China has been strengthening the regulation of sexual harassment of leading cadres, especially the strictening of the party's requirements after the 18th National Party Congress. The requirements of life discipline are becoming stricter. From the briefings of the officials of the fallen horses in recent years, many leading cadres are suspected of violating life disciplines, including color trading and money trading, But we also find that there are still some problems in preventing and controlling sexual harassment.

The danger of sexual harassment is still not in place. At present, due to the influence of traditional culture, many people do not understand the harmfulness of leading cadres' sexual harassment. They think that it is only a matter of personal moral quality. However, we believe that sexual harassment is not only a matter of moral quality, it is essentially an illegal act. It is an act that violates the autonomy of women's sexuality and is a form of gender discrimination.

The existing prevention and control measures are mainly based on negative moral evaluation and lack of rule of law. In the existing laws of our country, sexual harassment is only stipulated in Article 40 of the Law on the Protection of Women's Rights and Interests. Many existing regulatory measures often only conduct negative moral evaluations on the perpetrators, and such negative ethical evaluations sometimes hardly rise to the system. At the same time, due to the influence of traditional Chinese culture, many people think that the occurrence of sexual harassment is also closely related to the victims, and the victims themselves have anomie in behavior.

The protection of the victim is weak. The protection of victims of sexual harassment is weak, especially in terms of the burden of proof. The traditional principle of who advocates and who gives evidence is still used. Because of the hidden nature of sexual harassment, it is often difficult for victims to provide sufficient evidence. The EU's Regulations on the Implementation of Equal Treatment for Men and Women in 2002 stipulated that "the complainant can simply list the facts of the other party's harassment, and the respondent bears the main burden of proof, and the evidence of the respondent is final". At the same time, because the relationship between the victim and the infringer is relatively close, there is often a relationship between the superior and the subordinate. In a short period of time, it is difficult for the victim to claim his or her rights. When he wants to claim his own rights, the statute of limitations has often passed, and the criminal law of our country is sexually harassed. There are no clear regulatory measures for behaviors, especially for sputum, which has stricter standards of identification and sexual harassment often fails to meet this standard.

The scope of sexual harassment is not clearly defined. The American scholar Fett Grande proposed the most functional empirical definition in 1990, which was adopted by many academic harassment research institutes. The definition uses the specific form of sexual harassment and the concept of continuity to judge the sexual harassment behaviors encountered in daily life, and is divided into five levels according to the severity of the case: gender harassment, sexual provocation, sexual bribery, sexual shackles, and sexual assault. There are still some doubts about the specific implementation forms of sexual harassment. There are more physical sexual harassment and verbal sexual harassment in practice, but there are still many questions about whether some behaviors constitute sexual harassment, such as the behavior of yellow jokes at work. In 1986, the United States Federal High Court was at Meritor Savings Bank, FSB v. Sexual harassment cases were first heard in the Vinson case. The court cited the EEOC Policy Guidance on Sexual Harassment, which states that the main thrust of a sexual harassment case is to determine whether the alleged conduct is unwelcome. The court should examine whether the alleged conduct is unpopular, not whether the sexual intercourse that the victim actually participated in is voluntary. This is because, for exchange-type sexual harassment, especially academic harassment on university campuses, harassers often cite lure in academic achievement, paper publication, subject declaration, degree award, insurance research, employment recommendation, etc. Victims may be tolerant and agree to sexual harassment for their own interests or pressure, and acquiescence. In these cases, the victim did not resist on the surface, but the heart was not welcome for sexual harassment and thus adversely affected her (he). We believe that we should analyze from two aspects of subjective and objective. First, we must analyze the subjective aspect of the perpetrator to see whether the implementation behavior is to satisfy my unfair sexual interests. More importantly, it is to look at the objective aspect, that is, whether it is victimized. People cause sexual harm, and only if these two conditions are met at the same time, we believe that it constitutes sexual harassment.

\section{ANALYSIS ON THE CAUSES OF SEXUAL HARASSMENT BY LEADING CADRES}

Why the sexual harassment of leading cadres occurs and spread to some extent. The reasons we think are important are as follows.

The Influence of Bad Factors in Chinese Traditional Culture. The idea of male superiority and female humiliation in Chinese traditional culture has always been very serious. Women's personality has never been given due respect. Many men believe that sexual harassment is not a wrongful act, but a legal act, which is a normal behavior in 
interpersonal relationship. Such defects in understanding will make their behavior unconstrained.

The relationship between the upper and lower levels of the occupational field is unequal. The relationship between the upper and lower levels in China's current professional places is unequal. Many administrative agencies have not established a clear and up-to-date relationship. Leaders still play a big role in the promotion of lower-level positions, salary, and job development. Therefore, disguised form of personal attachment, and once this relationship is formed, female subordinates agree with the Nordic male leadership to implement sexual harassment, and it is difficult to effectively resist after sexual harassment.

The legal system is not perfect. Although the country began to prepare legislation against sexual harassment in the 1990s, progress in legislation has been slow. So far, legislation against sexual harassment has not been introduced. It is only the Women' s Rights Protection Law of 2005 and the Labor Protection of Female Workers in 2012. There are some unsystematic arguments in the special regulations. It is gratifying that many scholars of marriage law have been keenly aware of this issue in the compilation of the Civil Code. On August 27, 2018, the Civil Code personality submitted to the Standing Committee of the National People's Congress for consideration. The draft of the powers stipulates that, in violation of the will of others, sexual harassment of others by means of words, actions or affiliation, the victim may request the actor to bear civil liability according to law. The employer shall take reasonable measures at the workplace to prevent the occurrence of sexual assault. This is a major advancement in anti-sexual harassment legislation. For the first time, it has the content of anti-sexual harassment in the Civil Basic Law, and it emphasizes the content of affiliation. This shows that the legislators have special care for the sexual harassment formed by using their duties. However, we must also be soberly aware that such a provision is only a principled requirement, and further requires the constitutional requirements for sexual harassment in the single-line law, and the legal responsibility is further clearly defined.

\section{Countermeasures FOR LEAdING CADRES' SEXUAL HARASSMENT}

Confucius, a thinker in the Spring and Autumn Period, once said that "for politics and morality, such as Beichen, where the stars are arched," Sima Guang, a politician in the Song Dynasty, once pointed out that "the talent, the capital of Germany, and the talents of the Germans." This shows that from the beginning of ancient times, we have put forward relatively high requirements for the moral standards of officials. Comrade Xi Jinping also proposed that leading cadres should be strict and private, strengthen their moral cultivation, and lead cadres' sexual harassment has caused great image to the party. The negative impact has seriously damaged the relationship between the cadres and the masses. Therefore, in the context of strictly administering the party, it is necessary to strictly control the sexual harassment of leading cadres. We believe that we should proceed from the following aspects:

First, we must create a better public opinion atmosphere that controls sexual harassment. Comrade Xi Jinping pointed out that the rule of virtue and the rule of law must be combined with each other. Therefore, the issue of prevention and control of sexual harassment must also go hand in hand from both legal and moral aspects. Moreover, the rule of virtue plays a more fundamental role. It is not enough to curb sexual harassment by relying only on political and legal organs. It is necessary to rely on the broad masses of the people. Therefore, the atmosphere of public opinion is particularly important. However, some existing concepts are not very friendly to the victims. Many people think that the victims have a great influence on the occurrence of sexual harassment and cannot encourage the victims to bravely stand up and report sexual harassment.

Second, we must further strengthen institutional development, especially legislation. Because sexual harassment is essentially an illegal act, it needs to be addressed within the framework of the law. The definition of sexual harassment is a difficult problem in the world. In the Anglo-American legal system, it is often defined by jurisprudence. This method can better define the nature of sexual harassment. Of course, since China is a statute country, the jurisprudence is not formal. The source of the law, but the Supreme People's Court can guide local people's courts by issuing guidance cases and bulletin cases.

The legislation of sexual harassment should be regulated mainly from three aspects: criminal law, civil law and administrative law. Severe sexual harassment is treated as a crime in criminal law. The serious definition here should be judged from the serious consequences of the victim's sexual harassment, such as causing the victim to commit suicide. In the aspect of administrative law, sexual harassment should be defined as an act that should be subject to administrative punishment. In civil law, it should be characterized as an infringement. Therefore, when determining the specific behavior, it should be defined from the four elements of the infringement. The first is subjective fault. In terms of subjective faults, including deliberate and negligent forms, it is easier to identify deliberately in practice, but negligence is more difficult to determine. In particular, the distinction between legal and illegal behavior is difficult to determine in practice. The second is loss, what is the loss caused by sexual harassment. This issue is controversial. The current mainstream view is that sexual harassment violates the right to personality. However, there are different opinions on which personality right is specific. Foreign legislation is mainly determined to be an autonomous decision-making power, and some scholars believe that sexual harassment is a violation of personal dignity. The third is causality. How to determine the causal relationship between the behavior of the infringer and the victim is also a more complicated problem, which is sometimes related to the behavior of the infringer. The tolerance limits of different people are different. The words or behaviors are seen by ordinary people and do not constitute sexual harassment, but certain victims may feel uncomfortable and feel infringed. This involves how to judge 
[4] AUB NADINE, MACKINNON C A. Harassment of working women acase of sex discrimination [J]. Columbia Law Review, 1980, 80(8).

whether there is a causal relationship. Another important issue in civil law is whether the unit in which the infringer is located bears the tort liability. This actually involves the issue of alternative liability. At present, the tort law requires the liability of the employer to be responsible for the job, but sexual harassment is more difficult to identify as a job, because it is often not in the performance of duties. For example, in the United States, "early judicial decisions have always regarded teacher harassment as the "selfresponsibility" of the teacher, and reluctant to recognize the school's "agent responsibility" as an employer. Until the 1998 Geberser V. Lago Vista Indep), the Supreme Court finally established the agency responsibility of the school." In this case, the Federal Supreme Court "created a claim for compensation and placed joint and several liabilities on the school. If the student was sexually harassed and the school actually noticed or constructive notice, no measures were taken to prevent it. The school shall be liable for compensation. Therefore, it is necessary to strengthen the employer's responsibility to effectively curb sexual harassment. Therefore, the burden of proof of the employer should be reversed in the law, so that sexual harassment can be effectively prevented from being systematically prevented.

Third, we must steadily improve the status of women in the workplace. "The continuation of power relations based on unequal is due to the absence of operational rules and the lack of support for a culture of gender equality". After the founding of New China, women's social status has been significantly improved. Women in all walks of life have played an important role, and social participation has become more and more high. However, it is undeniable that women in many industries have ceilings. Moreover, the proportion of men in management is relatively large, and there is a certain limit on the space for women to rise. Therefore, we must further strengthen gender equality and eliminate some prejudice against professional women, so as to effectively improve the rising space of professional women, thus effectively curb the occurrence of sexual harassment.

\section{CONCLUSION}

The problem of sexual harassment of leading cadres has complicated historical, cultural and social reasons. Therefore, it is impossible to adopt a single means for its containment, but it must be comprehensively implemented. Therefore, the whole society should further agglomerate consensus and treat both German and French, so as to effectively prevent the occurrence of sexual harassment by leading cadres.

\section{REFERENCES}

[1] Tian Pingan, Luo Dongping. On the Distribution of Burden of Proof in Sexual Harassment Cases [J]. Guangdong Social Sciences 2006(6).

[2] Yang Lixin,Zhang Guohong.On the Construction of Legal Regulation System of Sexual Harassment Centered on the Protection of Private Rights[J].Journal of Fujian Normal University(Philosophy and Social Sciences),2005(1).

[3] DUNNE J V. Narrative coherence and its function in judicial decisionmaking and legislation [J]. The American Journal of Comparative Law,1996, 44 (3).
[5] ALUDI M A, BARICKMAN R B. Academic and workplace sexualharassment: a resource manual [M]. New York: State University of NewYork Press, 1991: 99- 114.

[6] ANDERSON E. Recent thinking about sexual harassment: a review es-say. Philosophy \& Public Affairs, 2006, 34(3).

[7] Zhang Xinbao, Gao Yanzhu. The main problems of legal regulation of sexual harassment [J]. Jurist, 2006 (4).

[8] Shen Yufei.The Generalization, Narrowing and Countermeasures of the Concept of "Sexual Harassment" [J]. Journal of Women's Studies,2004(1).

[9] Katherine A. McKinsey: "The Words Only", Wang Xiaohong Translation, Guilin: Guangxi Normal University Press, 2005 edition.

[10] Cao Yanchun, Liu Xiufen. Research on the common tort liability form of sexual harassment in the workplace $[\mathrm{J}]$. Politics and Law, 2010, (1). 